\title{
ESCOLASTICISMO Y HUMANISMO: UNA CONFRONTACION AJENA A LA "BATALLA DE LAS ARTES"
}

Silvia Magnavacca*

SÍNTESE - Esta comunicación se articula en tres partes. En la primera, se caracteriza el Humanismo mediante la exposición de sus principales notas comúnmente aceptadas, y, por oposición, el Escolasticismo visto por los humanistas. A continuación, se distingue entre este último y la Escolástica. En la segunda parte, se perfilan dos posiciones interpretativas: la de Kristeller, quien ve la confrontación entre Escolasticismo y Humanismo como una lucha entre disciplinas rivales, y la de Garin, que la considera una contraposición entre filosofias diversas. La comunicación procede, entonces, a ofrecer elementos que prueban la validez de la opinión de Garin contra la de Kristeller. Por último, en la conclusión, se exponen los fundamentos que justifican la posición asumida.

PALABRAS-LLAVE - humanismo, escolástica, filosofia.
ABSTRACT - The article is divided into three parts. The first part explains the main characteristics, generally accepted, of the humanism and contrasts it with the scholasticism as the humanists conceive it. Here is also made a distinction between scholasticism and scholastic teaching. The second part offers, on the one hand, the interpretation of Kristeller who sees the confrontation between scholasticism and humanism as a struggle of rival disciplines, and, on the other hand, that of Garin, who considers the confrontation as an opposition of different philosophies. Ther the author provides arguments in favor of the validity of Garin's opinion and finally are exposed the justifications of the taken stand.

KEY WORDS - humanism, scholasticism, philosophy.

Dado que los problemas concernientes al Humanismo de los siglos XIV y XV no sólo atañen a la periodización sino también a su misma definición, oue es una cuestión abierta y discutida aún por los especialistas, tomaremos como punto de partida, al menos, la recordación de lo que unánimemente se aceptan como sus caracteristicas fundamentales.

Ellas lo señalan como un fenómeno que, en primer lugar, consiste en un movimiento que, en el lapso que se extiende desde 1330 al 1630, aproximadamente, es el más característico e importante de dichos siglos, sin que esto, sin embargo, baste para que se lo considere un período propiamente dicho.

* Universidad de Buenos Aires. CONICET - Consejo de Investigaciones Científicas y Tecnológicas.

\begin{tabular}{|l|l|l|l|l|l|}
\hline VERITAS & Porto Alegre & v. 43 & $n^{\mathbf{0}} 3$ & Setembro 1998 & p. 683-691 \\
\hline
\end{tabular}


En segundo término, este movimiento es, sobre todo, cultural, siendo su nota central la intensificación del recurso a los valores de la civilización antigua, especialmente, la latina. ${ }^{1}$

En tercer lugar, hace mucho que está ya fuera de la discusión sobre el tema atribuir esa remisión y apertura hacia la Antigüedad clásica a la búsqueda de respuestas en el pasado ante la crisis peculiar manifestada desde las primeras décadas del siglo XIV. Si lo que hoy lamamos Occidente fue entonces en busca de sus orígenes, lo hizo porque ya no se sentía respaldado por su pasado más reciente. En este sentido, el Humanismo constituye el intento de Europa de reconocerse, indagando en su procedencia. Tal intento se inicia y tiene su epicentro en Italia precisamente porque en ella se gestó esa filiación. En este regreso a la cuna - guiado por una intencionalidad diferente de la que había hecho que los copistas medievales conservaran las obras antiguas - se verifica un encuentro nuevo con los libros fundamentales de Occidente, una relectura $\mathrm{y}$, por tanto, una revalorización distinta, dada por las diferentes circunstancias históricas desde las que se los lee. Esa apertura hacia el pasado no hubiera sido universal si sólo hubiera estado dirigida a los textos escritos en latín, esto es, en la lengua de los antepasados propios. Por el contrario, se volcó también a las fuentes orientales, helenísticas, hebraicas, buscando así las cunas de la humanidad y conformando de esa suerte la biblioteca universal del Mediterráneo en una sintesis brillante. Toda la sabiduría que potencialmente estaba disponible se capitaliza $y$, lo que es más importante, se asume como legítima herencia.

En cuarto término, el recurso a la Antigüedad no se emprende con el solo fin de imitarla; se apela a ella para asumir elementos y valores de la cultura antigua como factores determinantes de una renovación creativa. Esos valores no eran los expresados solamente en las obras literarias de la Antigüedad, sino también en las filosóficas, las juridicas, las artísticas y aun las científicas; de ahí que se caracterice el movimiento humanístico como fenómeno cultural.

En quinto lugar, tampoco está hoy en tela de juicio el fundamental carácter extrauniversitario que ostenta el Humanismo. Más aún, sus protagonistas pertenecen principal, aunque no exclusivamente, a élites laicas que acompañan al poder civil en busca de una cultura nueva que no respondiera sólo a la visión eclesiástica imperante todavía en los inicios de este lapso. Por eso, no constituye un fenómeno rural sino urbano, rastreable en ambientes aristocráticos, de la burguesía prominente y del aito clero.

Por último, una de las notas más importantes que caracterizan este fenómeno es su espiritu crítico que antecede y, de algún modo, posibilita su creatividad. Es sabido que la atracción que sobre los humanistas ejercían las obras clásicas fue nutriendo la pasión por los manuscritos que custodiaban la redacción más genuina y completa del pensamiento antiguo, pasión que redundó en la capacidad de distinguir textos auténticos y espurios. Pero este espiritu crítico terminó por calar más hondamente en el bagaje intelectual redescubierto: se fue afirmando la sensi-

1 En este sentido, coincidimós con la visión ofrecida por Alberto Tenenti en I Rinascimenti 13501630, Firenze, Le Monnier, 1981. 
bilidad para rever, por confrontación con lo antiguo, la escala de valores y la visión del mundo y del hombre que se había mantenido durante el Medioevo, pero que ya no ofrecía respuestas al desasosiego de una época en crisis. ${ }^{2}$ Así pues, los humanistas se valen de ese recurso a lo originario, de ese viaje al pasado, para satisfacer profundas exigencias de su propio presente. Por esa razón, el fenómeno humanístico, al que tantas veces se quiere reducir a un movimiento filológico, presenta una faceta filosófica, más aún, culmina en ella.

Este punto requiere algunas precisiones que, debido a la índole de este trabajo, deberán ser necesariamente breves: nunca se insistirá bastante en el hecho de que el rechazo humanístico del pasado reciente se dirige al empleo que:la Escolástica habia hecho de las corrientes filosóficas, no contra éstas en sí mismas, dado que muchas de ellas son reasumidas por los humanistas en una nueva clave. Por otra parte, lo anterior implica también que la reacción no se vuelve contra una tradición filosófica en particular, menos aún contra la aristotélica, como los trabajos de Ch. Schmitt, entre otros, han demostrado suficientemente. El mismo Kristeller advierte que "los historiadores del pensamiento occidental han expresado a menudo la idea de que el Renacimiento fue básicamente una edad de Platón, mientras que la Edad Media había sido una edad de Aristóteles. Este punto de vista ya no puede mantenerse sin considerables matices. A pesar de la amplia reacción contra la autoridad de Aristóteles, la tradición del aristotelismo siguió siendo muy fuerte a través dl período renacentista y en algunos sentidos, en Iugar de declinar, se incrementó". ${ }^{3}$ Como vemos, Kristeller menciona explícitamente una cuestión de autoridad, de peso argumental y de enfoque del aristotelismo en la universidad medieval, más que de doctrina propiamente dicha.

Ya desde el mismo fundador del Humanismo, Francesco Petrarca, se atacan abiertamente y con aciitud las tres líneas predominantes en los claustros: la línea especulativa, heredera de las grandes sintesis de Tomás y Escoto, que, concentrada en el afinamiento técnico de la discusión escolástica, se iba convirtiendo en una mera theologia disputatrix; la línea averroísta latina, tampoco ajena a cierto formalismo, que se habia ido configurando como philosophia naturalis y sumergia la scientia de anima en la scientia de natura, persistiendo, además, en la escisión practicada entre el orden filosófico y el de la fe; y la línea lógico-experimentalista, continuadora del ocamismo así como del experimentalismo de Bacon, que insistió en la atención a lo individual, lo observable y mensurable, proclamando que la única realidad que merecía el interés de la investigación humana era la empíricamente verificable. El mismo Petrarca llama a los cultores de la primera línea " $m u l-$ tiloqui"; a los de la segunda, "secuaces del perro Averroes"; mientras que considera a los de la tercera, exponentes del "agmen britannicum".

2 Es el enfoque defendido por Eugenio Garin con tanta solvencia y tantas veces, por ejemplo, en L'Umanesimo italiano. Filosofia e vita civile nel Rinascimento, Bari, 1952, Ritratti di umanisti, Firenze, Sansoni, 1967, o La cultura del Rinascimento, Milano, EST, 1996.

3 Kristeller, P.O., Renaissance Thought. The Classic, Scholastic and Humanistic Strains, New YorkLondon, Harper and Row, 1961, p. 24, subrayado nuestro; véase esp. cap. 2: "The Aristotelian Tradition". Cfr. también AAVV, Platon et Aristote a la Renaissance, Paris, Vrin, 1976; Schmitt, Ch., Problemi dell'aristotelismo rinascimentale, Napoli, Bibliopolis, 1983. 
Pero, así como no se impugna a Aristóteles sino ciertas formas escolásticas del aristotelismo, tampoco se impugna la serie de fundamentos del método escolástico: la prueba es la escrupulosidad con la que varios de los más autorizados humanistas, como Pico y Landino, se impusieron de ellos. Lo que se objeta es la forma esterilizante en que había caído dicho método, y sobre todo, su pretensión de constituir el único método válido, cosa de fundamental importancia a la hora de entrar de lleno en nuestro tema. Finalmente, se rechaza la limitación de la búsqueda intelectual a los claustros y su exclusividad en manos eclesiásticas.

Por todo esto, no se puede afirmar que el Humanismo se dirija contra la Escolástica propiamente dicha, sino que lo hace contra el escolasticismo, contraproponiendo, a la inversa de éste, una apertura hacia nuevas formas de indagación. La razón de ello obedece al hecho de que los movimientos culturales oficiales, universitarios, ya no respondian a las inquietudes de la época, en la que los hombres se interrogaban, fundamentalmente, por sí mismos, por su propia condición y por su destino; de ahi que se reivindique - y en esto, como en muchos otros puntos, la mediación ciceroniana ha sido fundamental - la figura de Sócrates, cuyo magisterio se opone ahora al que Aristóteles había ejercido durante un siglo y medio. Recuérdese, al respecto que todo esto culminará en el "Sancte Socrates, ora pro nobis" de Erasmo. ${ }^{4}$

Hasta aqui, hemos intentado resumir lo comúnmente aceptado sobre el movimiento humanistico. Este replanteo de la propia identidad lleva, como dijimos, a un regreso a la filiación, a una búsqueda de la cuna que, ceñida primero a la latina, se extiende después a otras. Pero este viaje a los orígenes requería también su propia hoja de ruta, presentaba exigencias metodológicas. Con arreglo a ellas, es posible distinguir el Humanismo italiano en fases que, por nuestra parte, presentaríamos como sigue:

a) la fase que enfatiza el rescate de la tradición literaria desde la latinidad, fase de intereses fundamentalmente éticos y políticos, que va de Petrarca a Leonardo Bruni. Si bien no es posible hacerla girar en torno del Studio fiorentino, porque lo excede, es inđưdable que éste cobró hacia el final de la presente fase una importancia crucial;

b) la fase en que se asume plenamente la exigencia metodológica, con la consecuencia de un desarrollo técnico de la filología; en ella se profundizan los intereses ético-religiosos y está representada de manera principal por Lorenzo Valla, cuya influencia llega a Erasmo;

c) la fase en que confluyen las dos anteriores para dar lugar a un replanteo profundo en el plano científico y filosófico; en ésta se integran a la corriente neoplatónica - que es su base principal - elementos aristotélicos, junto con el hermetismo alejandrino y las tradiciones orientales. Centrada en la Academia platónica de Florencia, señalaríamos como sus mayores representantes a Marsilio Ficino, Poliziano y Pico della Mirandola.

4 Cfr., por ej., Salutati, De fato I, 8; Manetti, G., De vita Socratis, passim. Al respecto, está todavía vigente el clásico de Ch. Deman, Socrate et Jesus, Paris, L'artisan du livre, 1944. 
Frente a este panorama y respecto del problema que nos ocupa, se dibujaron dos posiciones interpretativas: son las sustentadas por P.O. Kristeller, de un lado, y por Eugenio Garin y A. Lanza, de otro. Como hemos visto, el primero subraya que el Humanismo es aún en muchos aspectos un periodo aristotélico que continúa en parte las corrientes del aristotelismo medieval; pero además añade que ese ataque humanístico contra el escolasticismo no fue tanto un conflicto de filosofías opuestas cuanto una lucha entre disciplinas rivales. Garin y Lanza sostienen, en cambio, que, en primer lugar, el aristotelismo medieval se fue desmoronando paulatinamente bajo los golpes de una nueva mentalidad, cuya manifestación más evidente es la insistencia en el valor y la dignidad del hombre que, en literatura conduce al género de la biografia, y en las artes figurativas a la intransferible individualidad del retrato. En segundo término, ambos, reivindicando el carácter cultural del Renacimiento, afirman que el Humanismo renacentista no se juega en el campo de batalla de las artes sino en una nueva perspectiva sobre la realidad. ${ }^{5}$

Nos apresuramos a señalar nuestra coincidencia con este segundo enfoque, por razones que, sin embargo, han sido ejemplificadas pero no desarrolladas de modo suficientemente explícito por quienes lo sustentan.

Se ha de despejar primero la cuestión del aristotelismo y el platonismo humanísticos en oposición con lớs tardo-medievales, cuestión relacionada con la asi llamada "batalla de las artes" pero que no coincide exactamente con ella. Insistimos en que es una manera y un enfoque diferentes en la apelación a los grandes maestros de la Antigüedad lo que distingue el aristotelismo y el platonismo humanísticos de los que se dieron en el Miedioevo. Para ofrecer una ilustración al respecto, se puede recurrir a uno de los ejes por los que atraviesa la discusión filosófica en el siglo XV: la polémica sobre la preeminencia de la vida contemplativa o de la activa. A priori, se se podría suponer que los defensores de la vida contemplativa se apoyan en el platonismo y los de la activa en el aristotelismo. Sin embargo, no es asi: ambas líneas han sido frecuentadas en esta cuestión crucial en el Quattrocento. Humanistas que defienden la primera, como Pico y Plethon, apelan tanto a tesis aristotélicas como platónicas; mientras que un sombrío Ficino, extremando ciertas posiciones del neoplatonismo, exhorta a la fuga del mundo en su Theologia Platonica, o el luminoso Benivieni invita a la ascensión no menos platónica del alma en su Canzone d'amore que sigue el Banquete. En el otro extremo, en el de la defensa de la vida activa, Pandolfini se apoya en el Fedro para recordar que Sócrates nunca dejó su ciudad, porque un serio filosofar exige el diálogo civil; $\mathrm{y}$, por su parte, Landino en el De vita contemplativa et activa fundamenta en las Éticas Nicomaquea y Eudemia su afirmación de que quien huye de su propia sociedad no alcanza la condición humana.

Ahora bien, no solamente el uso que los humanistas hicieron de las obras filosóficas clásicas es distinto del tardo-medieval. Otra diferencia fundamental radica, en nuestra opinión, en el método al que apelaban. En este sentido, y para decirlo brevemente, se reemplaza el rigor - a la sazón vuelto despótico - de la dialéctica propia del escolasticismo por el carácter dialógico de la "conversazione civile"

5 Kristeller, P.O., op. cit:; Garin, E., La cultura del Rinascimento, Milano, EST, 1996; Lanza, A., Polemiche e berte letterarie nella Firenze del primo Quattrocento, Roma, Bulzoni, 1971. 
cuyo último modelo es precisamente el de las obras platónicas. Cabe repetir, una vez más, que, al acercarnos al Quattrocento, los procedimientos dialécticos del escolasticismo habian alcanzado un afinamiento formal que, a menudo, hacía olvidar el contenido de lo que se discutía. De ahí que los humanistas hayan mostrado, en general, una profunda desconfianza - que, a veces, rayaba el menosprecio y, otras, llegaba al ataque frontal - hacia dichos procedimientos que, se suponía, debian ser de acceso a la verdad. En el siglo que nos ocupa, la Universidad de París se destacaba especialmente en materia de theologia disputatrix, por lo que ese modus operandi metodológico era denominado el "stile parigino".

En realidad, las primeras reacciones contra la esterilidad de estas formas de la cultura "oficial", universitaria, provienen del campo de la literatura popular italiana, en cantares donde justamente se ridiculizaba a los dialécticos y su disciplina, la "loica". Ejemplo de ellos es el de Geta y Birria, servidores de un señor, Anfitrión, quien, abandonando esposa y propiedad, parte en compañía de sus siervos con el fin de ir a París a "aprender filosofía". Como ésta ofrecía la imagen de reducirse a vanas disputas dialécticas, el gárrulo personaje de Geta se jacta de haberse convertido en un sabio, diciendo: "Soy un gran lógico!", después de haber desgranado una serie de dislates en apariencia filosóficos. La reacción de la cultura oficial no se limitó al desdén. Francesco Landini es autor de un carmen latino en defensa justamente de la dialéctica ocamista, en el que el mismo Guillermo de Ockham aparece lamentado que la "nescia lingua procax" del vulgo denigre sus obras e ignore la dialéctica, sin la cual - dice - nada se puede conocer. ${ }^{6}$

¿Cuál era entonces la vía de acceso a la verdad y, en sentido inverso, la forma de expresión que contraproponían los humanistas? Para decirlo en una palabra, la respuesta es: la poesía y, en sentido más amplio, la prosa poética. Para examinar hasta qué punto este fenómeno es esencial al movimiento humanístico y lo atraviesa desde sus orígenes hasta su culminación, tomemos en consideración ambos momentos.

Ya en el Humanismo del siglo XIV la poesía se concibió como la clave que les permitía acceder a una de las preocupaciones que caracterizan este movimiento: la unidad del conocimiento, aun cuando dicha concepción desmintiera las tesis que - al menos, formalmente - habían sustentado al respecto Platón y Cicerón. Pero si el mismo Petrarca ubica a estos dos autores, junto a Séneca y Varrón, en la "corte de los poetas", no lo hace en el sentido técnico que la poesía tiene en literatura, sino porque ambos supieron aunar el más alto grado de especulación con el cultivo de una forma expresiva capaz de llegar armoniosa y persuasivamente a muchos. El último adverbio nos pone ya en camino de otra clave en esta cuestión, que en seguida retomaremos: la de la retórica. Detengámonos por un momento en estos primeros humanistas. No deja de ser significativo que Petrarca también incorpore a Aristóteles en esa corte, pensando especialmente, quizás, en el Aristóteles de la Poética. Sea de ello lo que fuere, constituye una prueba más de que si el primero de los humanistas rechaza con vehemencia ciertas formas en que había derivado el aristotelismo, no hace otro tanto con Aristóteles mismo. Por su parte,

6 Cfr. Lanza, A., op. cit. p. 46 y seg. 
Boccaccio postula la poesia como modalidad del saber laico convertido en filosofia, dando con ello la clave de la concepción humanística al respecto. Esto no obsta para que la caracterice aun como mensajera del Espiritu Santo. Más todavía, en las obras de los poetas clásicos, en quienes ve a los verdaderos teólogos de la Antigüedad, Boccaccio cree descubrir tres dimensiones: la histórica, la moral y la alegórica.

De todos modos, la "cuestión" de la poesía dio lugar a una serie de valoraciones humanísticas diversas sobre ella. Lo que todas tienen en común es la apelación a los grandes ejemplos de la tradición clásica. Contra esta posición se alineaban, sobre todo, los maestros universitarios que no sólo habian relegado la poesía a un puesto secundario, sino que miraban con recelo todo lo que despertara el recuerdo del mundo pagano. No obstante, forma parte sustancial del fenómeno humanístico, de un lado, el papel protagónico que va adquiriendo el poeta en la nueva realidad civil; de otro, la revaloración de la poesía como medio más eficaz para transmitir, mediante la armonía y la musicalidad, los contenidos más diversos de la indagación humana. En la plenitud del Humanismo, para acudir ahora al otro extremo de los mencionados, la citada Canción de amor de Benivieni sobre la ascensión platónica del alma es ejemplo cabal de esto.

Todo ello motivó, al mismo tiempo y por una parte, la afinación de criterios hermeneúticos en la actividad crítica, prevaleciendo en ellos la interpretación filosófica de los poetas antiguos. ${ }^{7}$ Así, los dos últimos libros de las Disputationes de Cristoforo Landino sobre el mítico viaje del Eneas virgiliano son, en realidad, una obra filosófica acerca de la condición y del fin del hombre. ${ }^{8}$ De esta manera, la poesía cobró jerarquía de llave de oro que permitía la apertura a la verdad. Durante el Quattrocento, pues, esta concepción se encuentra ya arraigada entre los humanistas, de modo que subsiste no sólo como doctrina explícita sino, sobre todo, como actitud.

En este sentido, si hubo en el seno del movimiento humanístico una "batalla de las artes" fue, en todo caso, la que se dio entre las disciplinas más estrechamente vinculadas con la poesía entendida, como indicábamos, en su significado más amplio: la retórica y la filología. En lo que hace a la primera, su importancia radica en la que adquirió la discusión en el ámbito del así llamado "Umanesimo civile", es decir en ese campo donde se polemizó sobre distintos aspectos que hacen a la dimensión social del hombre. En lo que toca a la segunda, su papel fue fundamental en la dimensión crítica del Humanismo, especialmente, en la crítica histórica - recordemos el "caso Lorenzo Valla" - y, como señalábamos, también en la literaria.

7 Cfr. Ronconi, G., Le onigini delle dispute umanistiche sulla poesia, Roma, Bulzoni, 1976.

8 Véanse sobre este tema los trabajos de Roberto Cardini, por ej., "Cristoforo Landino e l'Umanesimo volgare", en La Rassegna della letteratura italiana, LXXII (1968) 267-306; "Cristoforo Landino e la poesia”, en ibid. LXXIV (1970) 273-358; La critica del Landino, Firenze, Sansoni, 1971; "Landino e Dante", en Rinascimento XXX (1990) 175-190. 
Pero se ha de insistir en dos hechos: en primer término, que son siempre disciplinas al servicio de la indagación filosófica. En este plano, nada puede ser más significativo - ni más demoledor del prejuicio que ve en el Humanismo un trivial movimiento literario - que la defensa que Pico hace del latín escolástico en su célebre polémica con Ermolao Barbaro. En ella traza los límites entre retórica y elocuencia, para sostener, en definitiva, que ese latin fue elocuente, precisamente en la medida en que expresó con justeza el aritmético y neto pensamiento escolástico. Subrayemos, de paso, que cita a autores del siglo de oro de la Escolástica y no del escolasticismo. En una de las instancias de esa polémica declara preferir una liave de madera que le abra la puerta de la verdad a una de oro que no lo consiga ${ }^{9}$ Con todo, es él mismo quien redacta lo que se ha considerado "el manifiesto del Renacimiento", o sea, el De hominis dignitate en clave poética y apelando muchas veces a recursos retóricos.

El segundo hecho a señalar concierne al marco en el que se desarrolla el movimiento humanístico en confrontación con aquel que contiene el tardo-medieval. En éste, la nítida y exclusiva referencia institucional pautaba no sólo los campos de indagación sino también el método de enseñanza e investigación. Entre los humanistas - aunque limitados por el poder político, especialmente el mediceo, en lo que toca a ciertos temas - se dio una mayor libertad que reduncó en otro modus operandi y, a la postre, en otra forma mentis en el abordaje de las cuestiones filosóficas. Esto es aigo que los defensores de una aproximación al Humanismo desde la lucha entre disciplinas rivales no tienen en cuenta. Es, como advertíamos al comienzo, el caso de Kristeller. En efecto, en su famoso artículo sobre Petrarca, Kristeller declara estar "dispuesto a interpretar el conflicto entre el Humanismo y la Escolástica [...] como una fase muy interesante en la batalla de las artes o en la lucha entre las facultades...", después de haber afirmado que, "mientras que los humanistas tenían como campo de acción la gramática, la retórica, la poesia, la historia y la filosofía moral, sus contemporáneos escolásticos abarcaban la teología, la jurisprudencia, las matemáticas, la medicina, la lógica y la filosofía natural". ${ }^{10}$ Pero, además de todo lo ya dicho hasta aquí, no es cierto que los humanistas no hayan incursionado en la teología - piénsese en el Heptaplus o en la misma Theologia platonica - ni, en sentido inverso, que algunos médicos no hayan sido humanistas, tal es, por ejemplo, el caso de Marsilio Ficino.

Entre Humanismo y Escolasticismo hay un conflicto más profundo que deriva no sólo de una diferencia de intereses sino de cosmovisiones. Quienes insisten en tratar de aprehender su polifacética riqueza a través de la batalla de las artes lo hacen, tal vez, porque, descontextualizando históricamente la evolución del pen-

9 Cfr. Breen, Q., "G. Pico della Mirandola on the Conflict of Philosophy and Rhetoric", en Journal of the History of Ideas, 3, X (1952) 384-426. Breen no parece haber percibido en toda su dimensión las implicancias de la posición piquiana; de lo contrario, hubiera titulado de otra manera su artículo. La cuestión fue redimensionada por Garin en su comunicación al Congreso Internacional sobre el pensamiento de Pico della Mirandola, clebrado en 1964. Cfr. nota 11.

10 "Petrarch, Humanism and Scholastic in Venice", en La civiltà veneziana del Trecento, Venezia, Sansoni, 1956, 147-179. 
samiento filosófico, han proyectado sobre el movimiento humanístico categorías interpretativas sólo válidas para la Escolástica medieval, ni siquiera para todo el pensamiento de la Edad Media.

Por eso, hacemos nuestra la posición de Eugenio Garin quien, polemizando con Kristeller, ha dicho: "Yo no identifico la cultura escolástica con la filosofía, y la cultura humanística con la gramática, la retórica y la literatura”. El choque entre ambas culturas "no se puede reducir a la pelea entre gramáticos y filósofos, sino que es él mismo un choque entre filósofos y filósofos". ${ }^{11}$

Por nuestra parte, añadiriamos que cada orientación, escuela, corriente o movimiento filosófico encuentra sus propias vías de acceso al pensamiento - ciertamente no casuales - y su propio cauce expresivo, pero limitar a este último su contenido doctrinal es, por lo menos, hacer una lectura superficial.

El mismo Dante quien, en su Comedia, se yergue como la gran síntesis de la Escolástica y, a la vez, como heraldo del Humanismo que se aproximaba, reivindica, en la conocida carta a Can Grande della Scala, el carácter filosófico de su Poema. ${ }^{12}$ ¿Acaso él negaría el mismo carácter a tantas obras de los humanistas que lo sucedieron?

Creemos que no.

11 "Le interpretazioni del pensiero di Giovanni Pico", en L'opera e il pensiero di G. Pico della Mirandola, Firenze, Ist. Naz. di Studi sul Rinascimento, 1965, p. 32-33. Las traducciones nos pertenecen.

12 Cfr. Paolazzi, C. "Nozione di Commedia e tradizione retorica nella dantsca Epistola a Cangrande", en Suti Danteschi L (1990) p p. 87-186. Después de haber desdejado toda duda acerca de la autenticidad de la carta, Paoiazzi transcribe el texto de Dante, donde éste define la írdole del Poema, cuya tercera y última parte dedica al destinatario, diciendo que "el género filosófico según ei que se procede tanto en la totalidad de ia obra como en la parte [dedicada] es el de la actividad moral o ética" [Genus vero philosophiae, sub quo hic in toto et parte proceditur, est morale negotium sive ethical. Subrayado nuestro. 